\title{
Relaxation of proximal and distal isolated human bronchi by halothane, isoflurane and desflurane
}

\author{
F.J. Mercier*,\#, E. Naline*, M. Bardou*, O. Georges ${ }^{\star}$, A. Denjean ${ }^{+}$, D. Benhamoü, C. Advenier*
}

Relaxation of proximal and distal isolated human bronchi by halothane, isoflurane and desflurane. F.J. Mercier, E. Naline, M. Bardou, O. Georges, A. Denjean, D. Benhamou, C. Advenier. (C) ERS Journals Ltd 2002.

ABSTRACT: Volatile anaesthetics relax airway smooth muscle in vitro. The amount of relaxation might depend on the type and concentration of volatile anaesthetics, the calibre and precontraction level of the bronchi, and also on the species considered. These effects were investigated on isolated human bronchi.

Isometric relaxations produced by halothane, isoflurane and desflurane bubbled on human bronchial rings precontracted with carbachol were recorded and compared with time controls.

Volatile anaesthetics induced a concentration-dependent relaxation at $0.66,1.33$ and 2 minimum alveolar concentration (MAC). The relaxation was greater in mildly (carbachol $3 \times 10^{-7} \mathrm{M}$ ) than in highly (carbachol $2 \times 10^{-6} \mathrm{M}$ ) precontracted bronchi. Halothane was more potent in relaxing distal as compared to proximal bronchi; this differential effect was less pronounced with isoflurane and not observed with desflurane. While the three volatile anaesthetics induced similar relaxation on proximal bronchi, halothane was significantly more potent than desflurane on distal bronchi, with isoflurane being intermediate. The relaxation induced by $1.33 \mathrm{MAC}$ of halothane, isoflurane and desflurane on moderately precontracted distal bronchi (carbachol $\left.1 \times 10^{-6} \mathrm{M}\right)$ was attenuated by pretreatment with glibenclamide $1 \times 10^{-5} \mathrm{M}$.

In conclusion, halothane, isoflurane and desflurane exert direct but differential relaxant effects on human isolated bronchial smooth muscle. This may provide supplemental bronchodilation during anaesthesia. Although adenosine triphosphatesensitive $\mathrm{K}^{+}$channels are involved in these relaxant effects, they are unlikely to explain the observed differences between the three volatile anaesthetics. Eur Respir J 2002; 20: 286-292.
*University of Medicine Paris-Ouest and UFR Biomédicale des St Pères, Paris, ${ }^{\#}$ Department of Anaesthesia, Antoine Béclère Hospital, Clamart cedex, Laboratoire Lab-Guigui et Associés, Paris and ${ }^{+}$Service d'Explorations Fonctionnelles, CHU de Poitiers, Poitiers, France.

Correspondence: F.J. Mercier, Dépt d'Anesthésie-Réanimation, Hôpital Antoine Béclère, 157 rue de la Porte de Trivaux, 92141 Clamart Cedex, France.

Fax: 33145374985

E-mail: frederic.mercier@abc.

ap-hop-paris.fr

Keywords: Adenosine-triphosphate sensitive $\mathrm{K}^{+}$channels

airway smooth muscle

asthma

desflurane

halothane

isoflurane

Received: August 232001

Accepted after revision: March 52002
Halothane and isoflurane are well-established bronchodilators in vivo both in animals [1-5] and humans $[6,7]$. Part of this bronchodilation is due to a direct effect on airway smooth muscle. For example, in dogs in vivo, the direct relaxant effect of halothane on airway smooth muscle contributed as much as the indirect effect on the vagal pathway [4]. These direct relaxant effects in vivo have been reproduced in vitro in many animal studies [8-19]. However, the intensity of the relaxation in vitro varies widely among studies. Factors that may explain these variations include: 1) anaesthetic concentration; 2) level of precontraction and contractile agonist used [11]; 3) airway calibre $[13,19,20]$; 4) differences in efficacy between volatile anaesthetics [7, 13, 17, 20]; and 5) animal species. This latter factor might be particularly important, and so far, no in vitro studies involving volatile anaesthetics appear to be available on human airway smooth muscle.

Desflurane, a more recent volatile anaesthetic, has some interesting properties including rapid onset/ offset of action. However, breath-holding, partial laryngospasm and coughing have been reported during induction of anaesthesia with desflurane in humans [21]. Such irritant effects on the upper airways do not seem to occur during anaesthesia in animals [22]. In addition, desflurane appears highly effective in relaxing canine, rat, and guinea pig airway smooth muscle in vitro $[13,17,18]$, whereas it does not produce bronchodilation during anaesthesia in humans [23].

The rationale of this study was to clarify the previously-mentioned conflicting data, by checking the relaxant effects of volatile anaesthetics previously described in animal airway smooth muscle, the factors that may influence these effects, and the effect of desflurane on human airway smooth muscle specifically. Therefore, the relaxant effects of three increasing concentrations of halothane, isoflurane and desflurane were investigated on human bronchial rings at mild and high levels of precontraction. In addition, the effects of these anaesthetics on proximal and distal bronchi were compared. Finally, the influence of pretreatment with the adenosine-triphosphate sensitive $\mathrm{K}^{+}$channel $\left(\mathrm{K}_{\mathrm{ATP}}\right)$ channel blocker glibenclamide was examined because recent evidence in animal 
studies suggests that activation of $\mathrm{K}_{\mathrm{ATP}}$ channels might play a prominent role in volatile anaesthetic mechanism of action $[24,25]$.

\section{Materials and methods}

\section{Human bronchial tissue preparation}

Human lung tissues were obtained from patients $(n=30)$ undergoing surgery for lung cancer. They were taken as far away as possible from the malignancy, dissected free of parenchyma and placed immediately in Krebs solution (composition in $\mathrm{mM}: \mathrm{NaCl} 119$, $\mathrm{KCl}$ 5.4, $\mathrm{CaCl}_{2}$ 2.5, $\mathrm{KH}_{2} \mathrm{PO}_{4} \quad 0.6, \mathrm{MgSO}_{4} \quad 1.2$, $\mathrm{NaHCO}_{3} 25$ and glucose 11.7). The Krebs solution had been cooled previously at $4{ }^{\circ} \mathrm{C}$ and aerated with carbogen $(95 \%$ oxygen and $5 \%$ carbon dioxide) to maintain a $\mathrm{pH}$ of 7.4. The tissue was stored at the same temperature and the experiment was carried out within $24 \mathrm{~h}$. Eight rings, 4-6 mm in length, were prepared from each specimen. The rings were obtained either from proximal bronchi (inner diameter of 4 $5 \mathrm{~mm}$ ) or distal bronchi (inner diameter of 0.5-1 mm). Each set of eight rings was suspended under an initial load of $2.0 \mathrm{~g}$ in $10-\mathrm{mL}$ organ baths containing Krebs solution, temperature controlled at $37^{\circ} \mathrm{C}$ and continuously gassed with carbogen. The tissues were allowed to equilibrate for $1 \mathrm{~h}$ with Krebs solution washing every $10-15 \mathrm{~min}$. Changes in isometric force were measured continuously with UF1-Pioden strain gauges (Phymep, Paris, France) and amplifiers (EMKA, Paris, France) and were displayed on recorders (Linseis, Illkirch, France).

\section{Volatile anaesthetic delivery to the tissue preparation}

The three volatile anaesthetics tested, i.e. halothane, isoflurane and desflurane, were introduced directly in vitro via the bubbling carbogen, as described in a previous study [12]. A pair of rings served as a time control and were bubbled with carbogen only throughout the experiment. During assessment of volatile anaesthetic effects, the three other pairs of rings were bubbled with either halothane, isoflurane or desflurane delivered by Fluotec $3 \AA$ and Isotec 3 (Ohmeda, Trappes, France) and Devapor $\AA$ (Dräger, Antony, France) calibrated vaporisers respectively, with carbogen used as gas vehicle. The anaesthetic concentrations were directly expressed in minimum alveolar concentration (MAC, i.e. concentration of an inhaled anaesthetic sufficient to keep $50 \%$ of subjects from moving in response to a surgical incision [26]), with 1 MAC halothane $=0.75 \%, 1$ MAC isoflurane $=1.2 \%$ and 1 MAC desflurane $=6 \%$. Indeed, it has been shown that anaesthetic partial pressures in vitro are close to those needed in vivo to obtain a target anaesthetic concentration in tissues [27]. The anaesthetic concentrations, as well as the $\mathrm{O}_{2}$ and $\mathrm{CO}_{2}$ concentrations, were controlled just before entering the organ baths by the infrared absorption technique (Capnomac Datex; Ohmeda) and adjusted as needed. The bubbling was set at a relatively high rate $\left(20-30 \mathrm{~mL} \cdot \mathrm{min}^{-1}\right)$ to quickly saturate the $10-\mathrm{mL}$ Krebs solution and was maintained precisely at the same rate with a flowmeter (D1X C29430; Bioblock scientific, Illkirch, France) positioned just before each organ bath. Under similar conditions, BAZIL et al. [27] have shown that equilibrium of volatile anaesthetics (halothane) is rapid, as it is reached in only $5 \mathrm{~min}$ into Krebs solution and in 20-30 min into tissues.

\section{Protocols}

Protocols are shown in figure 1. In all experiments, after the first hour of equilibration, the rings were contracted to maximal tension with acetylcholine $1 \times 10^{-3} \mathrm{M}$ and then allowed to equilibrate back to resting tension for another hour with Krebs solution washing every $10-15 \mathrm{~min}$. Only one response to halothane, isoflurane, desflurane or carbogen alone (used as time control) was recorded on each ring. Throughout this paper, $\mathrm{N}$ denotes the number of patients whereas $\mathrm{n}$ denotes the number of bronchial rings obtained from these patients. Maximal relaxation of the bronchial rings was determined at the end of each experiment using theophylline $3 \times 10^{-3} \mathrm{M}$.

Cumulative concentration/response curves of halothane, isoflurane and desflurane on proximalldistal bronchial rings mildly precontracted with carbachol. Sustained mild contractions were elicited with carbachol $3 \times 10^{-7} \mathrm{M}$ on four proximal and four distal bronchial rings obtained from the same specimen. When the plateau was reached $20-30$ min later, halothane, isoflurane and desflurane were introduced at an increasing concentration of $0.66,1.33$ and 2 MAC during three
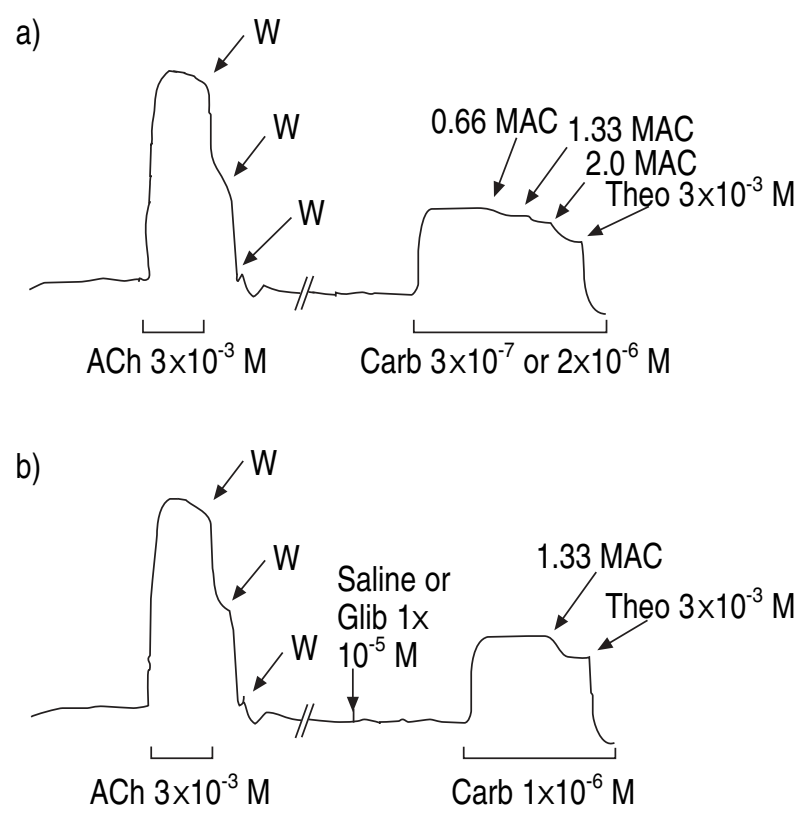

Fig. 1.-Schematic representations of the experiments. a) Responses to increasing concentrations of volatile anaesthetics and b) effects of pretreatment with glibenclamide (Glib). Anaesthetic concentrations are expressed in minimum alveolar concentration (MAC). ACh: acetylcholine; W: Krebs solution washing; Carb: carbachol; Theo: theophylline. 
consecutive 30-40-min periods, at the end of which the anaesthetic relaxant effects were assessed $(\mathrm{N}=10, \mathrm{n}=80)$.

Cumulative concentration/response curves of halothane, isoflurane and desflurane on proximalldistal bronchial rings highly precontracted with carbachol. The same previously-mentioned protocol was used to assess the relaxant effects of halothane, isoflurane and desflurane on rings highly precontracted with carbachol $2 \times 10^{-6} \mathrm{M}$ $(\mathrm{N}=12, \mathrm{n}=96)$.

Effect of 1.33 MAC of halothane, isoflurane and desflurane on moderate carbachol-induced contractions in distal bronchial rings pretreated with glibenclamide. Four distal bronchial rings were pretreated with the $\mathrm{K}_{\mathrm{ATP}}$ channel blocker glibenclamide $1 \times 10^{-5} \mathrm{M}$, whereas four other distal bronchial rings from the same specimen served as controls. Sustained moderate contractions with carbachol $1 \times 10^{-6} \mathrm{M}$ were elicited 45 min later. When the plateau was reached, halothane, isoflurane and desflurane were introduced at a fixed concentration of 1.33 MAC for another 45-min period, at the end of which anaesthetic relaxant effects were assessed $(\mathrm{N}=8, \mathrm{n}=64)$.

\section{Drugs}

Halothane was obtained from Belamont (Paris, France), isoflurane from Abbott (Rungis, France) and desflurane from Kabi-Pharmacia (St Quentin en Yvelines, France). Volatile anaesthetic concentrations are directly expressed in MAC. The other chemicals were acetylcholine, carbachol and glibenclamide, purchased from Sigma-Aldrich (St Quentin Fallavier, France), and theophylline, purchased from Bruneau (Paris, France). Acetylcholine and carbachol were dissolved in distilled water, whereas glibenclamide was dissolved in absolute ethanol. These chemicals were then diluted in Krebs solution and their concentration expressed as final molar concentration in organ baths.

\section{Expression of the results and statistical analysis}

Relaxations elicited by volatile anaesthetics are expressed as percentage of maximal relaxation produced by theophylline $3 \times 10^{-3} \mathrm{M}$. The time-control variation from each specimen was subtracted to keep only the actual relaxation induced by the volatile anaesthetics.

Data are expressed as mean \pm SEM. An analysis of variance for repeated measures was used to assess: 1) concentration-dependent effects of volatile anaesthetics; 2) effects of anaesthetics on highly versus mildly precontracted bronchi; 3) distal versus proximal effects of anaesthetics; and 4) comparative effects of halothane, isoflurane and desflurane (figs. 2a-d). Factorial analysis of variance was used to assess the influence of pretreatment with glibenclamide $1 \times 10^{-5} \mathrm{M}$ on anaesthetic effects (fig. 3). Fisher's protected least significant difference (PLSD) post hoc tests were used for two-by-two comparisons between halothane, isoflurane and desflurane. A p-value $<0.05$ was considered significant.

\section{Results}

In each subset of experiments, the gases studied (halothane, isoflurane, desflurane or carbogen used as time control) were administered on bronchi that had actually achieved comparable levels of contractions with carbachol $\left(3 \times 10^{-7} \mathrm{M}, 2 \times 10^{-6} \mathrm{M}\right.$ or $\left.1 \times 10^{-6} \mathrm{M}\right)$ $(\mathrm{p}>0.05)$.

Effects of precontraction level, airway calibre and concentration of volatile anaesthetics

Mildly precontracted bronchi (with carbachol $\left.3 \times 10^{-7} \mathrm{M}\right)$ reached $31 \pm 2 \%$ of maximal response to acetylcholine $1 \times 10^{-3} \mathrm{M}$, whereas highly precontracted bronchi (with carbachol $2 \times 10^{-6} \mathrm{M}$ ) reached $72 \pm 1 \%$ of maximal response. Time control variations subtracted from figure 2 are given in table 1.

Volatile anaesthetics relaxed human bronchi in a concentration-dependent manner at $0.66,1.33$ and 2 MAC $(p<0.0001)$ (figs. $2 a-d)$. The relaxation was greater in mildly than in highly precontracted bronchi $(\mathrm{p}<0.0001)$ (figs. $2 \mathrm{a}$ and $\mathrm{b}$ versus figs. $2 \mathrm{c}$ and $\mathrm{d}$ ). Halothane relaxed the distal bronchi more than the proximal bronchi $(\mathrm{p}=0.008)$. This differential effect on airway calibre was less pronounced and at limit of significance with isoflurane $(\mathrm{p}=0.056)$ but was not observed at all with desflurane $(\mathrm{p}=0.93)$ (figs. $2 \mathrm{~b}$ and $\mathrm{d}$ versus figs. 2 a and c). While the three volatile anaesthetics induced similar relaxation on proximal bronchi $(\mathrm{p}=0.81)$ (figs. 2a and $\mathrm{c}$ ), halothane was significantly more effective than desflurane on distal bronchi with isoflurane being intermediate $(\mathrm{p}=0.008)$ (figs. $2 \mathrm{~b}$ and d).

Effects of glibenclamide pretreatment on volatile anaesthesia-induced relaxation

Precontracted bronchi (with carbachol $1 \times 10^{-6} \mathrm{M}$ ) reached $58 \pm 2 \%$ of maximal response to acetylcholine $1 \times 10^{-3} \mathrm{M}$. Time-control variations with or without glibenclamide pretreatment (subtracted from fig. 3) were not significant (mean relaxation $=2.75 \%, \mathrm{p}=0.14$ ).

The relaxation produced by 1.33 MAC halothane, isoflurane and desflurane on these moderately precontracted distal bronchi was significantly attenuated by pretreatment with glibenclamide $1 \times 10^{-5} \mathrm{M}(\mathrm{p}=$ 0.008 versus no pretreatment) (fig. 3). This attenuation by glibenclamide was not significantly different between volatile anaesthetics $(-50 \%,-39 \%,-55 \%$ for reduction of halothane, isoflurane and desfluraneinduced relaxation, respectively, $\mathrm{p}=0.57$ ).

\section{Discussion}

There are many studies available on the relaxant effects produced by volatile anaesthetics directly 
a)

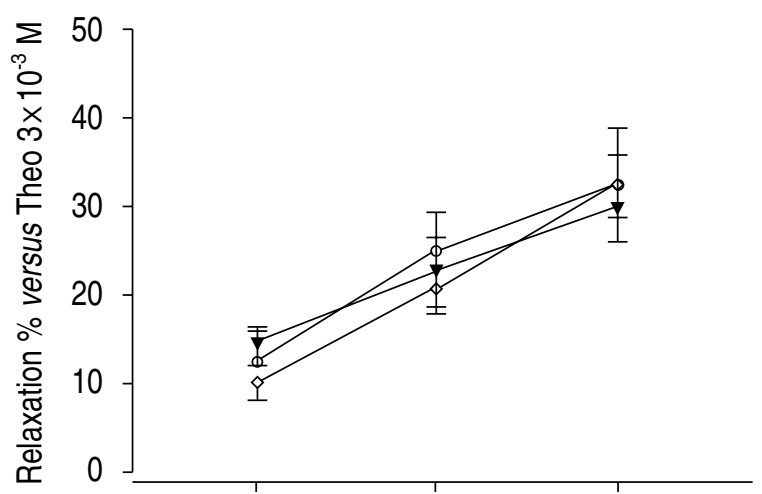

c)

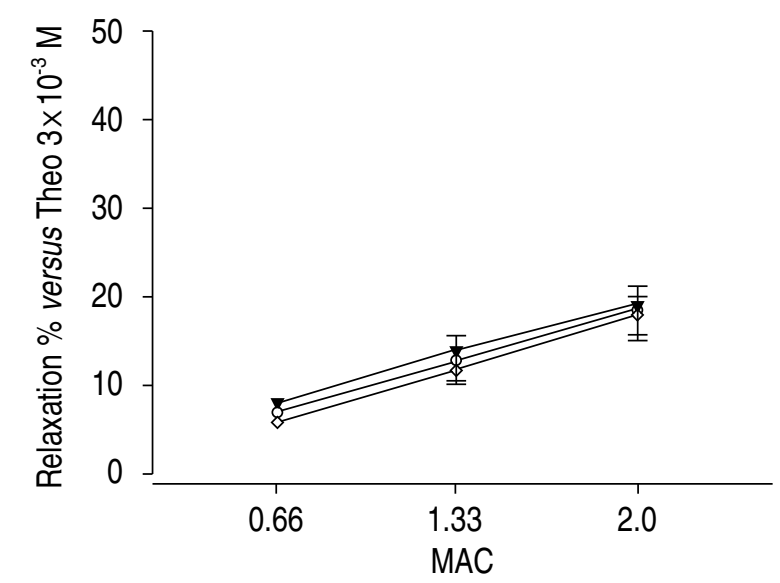

b)

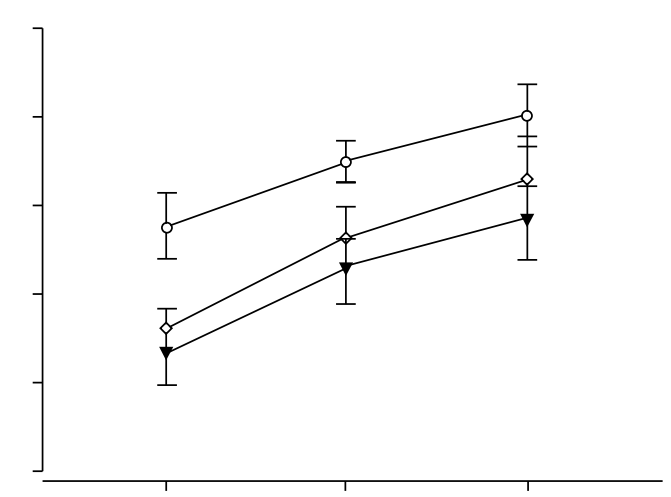

d)

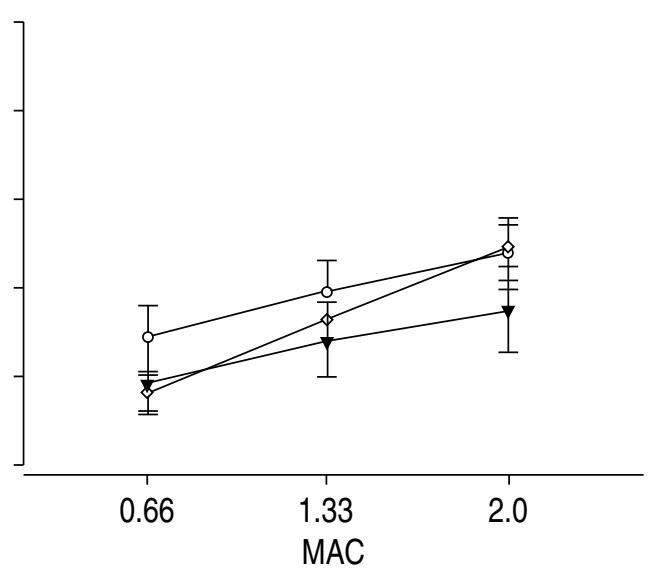

Fig. 2.-Relaxation produced by increasing cumulative concentrations of halothane $(\bigcirc)$, isoflurane $(\diamond)$ and desflurane $(\boldsymbol{\nabla})$ administered on precontracted human bronchi. All volatile anaesthetics produced a significant concentration-dependent relaxation $(\mathrm{p}<0.0001)$. The relaxation was more pronounced in mildly (a and b carbachol $3 \times 10^{-7} \mathrm{M}$ ) than highly (c and $\mathrm{d}$ carbachol $2 \times 10^{-6} \mathrm{M}$ ) precontracted bronchi $(\mathrm{p}<0.0001)$. Volatile anaesthetics were equally effective on proximal bronchi (a and $\mathrm{c}, \mathrm{p}=0.81)$. Halothane was significantly more effective than desflurane on distal bronchi, with isoflurane being intermediate ( $b$ and $\mathrm{d}, \mathrm{p}=0.008$ ) (halothane/desflurane: $\mathrm{p}=0.003$; halothane/ isoflurane: $\mathrm{p}=0.06$; isoflurane/desflurane: $\mathrm{p}=0.22$ ). Theo: theophylline. MAC: minimum alveolar concentration.

administered in vitro on isolated airway smooth muscle [8-19]. However, few of them have been performed on distal airway smooth muscle $[13,16,17,19]$ or have

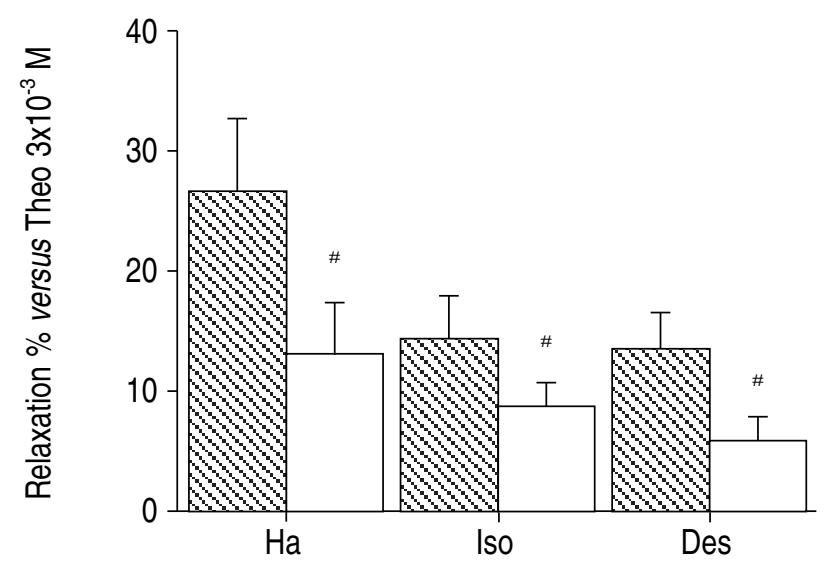

Fig. 3.-Effect of glibenclamide pretreatment $\left(\square 1 \times 10^{-5} \mathrm{M}\right)$ on the relaxation produced by 1.33 minimum alveolar concentration halothane (Ha), isoflurane (Iso) and desflurane (Des) compared to control $(\mathbb{\nabla})$. The distal human bronchi were moderately precontracted with carbachol $1 \times 10^{-6} \mathrm{M}$. Theo: theophylline. ${ }^{\#}$ : $\mathrm{p}=0.008$ for pretreatment versus no pretreatment (and $\mathrm{p}=0.57$ for interaction between glibenclamide and anaesthetics). involved desflurane $[13,17,18]$. Moreover, to the current authors' knowledge, none were performed on human airway smooth muscle. In the present study, it was found that halothane, isoflurane and desflurane exerted similar concentration-dependent relaxant effects on human proximal airway smooth muscle, whereas differential effects with these anaesthetics were observed on distal bronchi (fig. 2).

The concentration-dependent relaxant effect of volatile anaesthetics on human airway smooth muscle within clinical useful concentrations (0.66-2.0 MAC) is in accordance with most of the studies performed on animal airway smooth muscle [11, 13, 14, 16-19]. However, Korenaga et al. [8] found that dog tracheal airway smooth muscle contraction was significantly reduced by $1.2 \mathrm{MAC}$ of halothane only when contraction was indirectly evoked by nerve stimulation. BRICHANT et al. [9] also initially reported similar results in the same animal model, i.e. a marked concentration-dependent effect of halothane (from 0.3 to $2.4 \mathrm{MAC}$ ) on neurally-induced contractions as opposed to a very small and ceiling effect at 1 MAC on acetylcholine-induced contractions. Conversely, the same group observed a marked concentrationdependent relaxation with 1 and 2 MAC of halothane applied on bronchial segments directly prestimulated with carbachol [10]. One of the reasons for these 
Table 1.-Evolution of the time-control precontracted bronchi during the cumulative concentration/response curves to volatile anaesthetics (depicted in figs. $2 a-d$ )

\begin{tabular}{lrrr}
\hline Time points & 0.66 MAC & 1.33 MAC & 2.0 MAC \\
\hline Carb 3 $\times 10^{-7}$ proximal bronchi & $-0.1 \pm 1.5$ & $1.5 \pm 2.4$ & $1.0 \pm 3.7$ \\
Carb 3 $\times 10^{-7}$ distal bronchi & $1.0 \pm 1.8$ & $0.7 \pm 3.3$ & $1.6 \pm 4.7$ \\
Carb $2 \times 10^{-6}$ proximal bronchi & $3.5 \pm 0.7$ & $8.4 \pm 1.8$ & $12.7 \pm 2.7$ \\
Carb $2 \times 10^{-6}$ distal bronchi & $5.4 \pm 1.0$ & $12.1 \pm 2.2$ & $16.5 \pm 3.0$ \\
\hline
\end{tabular}

Data are presented as mean \pm SEM percentage of maximal relaxation produced by theophylline $3 \times 10^{-3} \mathrm{M}$ at the end of the experiment. MAC: minimum alveolar concentration (a positive value represents a spontaneous relaxation with time whereas a negative value represents a spontaneous contraction; Carb: carbachol. No spontaneous relaxation in mildly (carbachol $\left.3 \times 10^{-7}\right)$ precontracted bronchi $(\mathrm{p}=0.86)$. Spontaneous relaxation in highly (carbachol $2 \times 10^{-6}$ ) precontracted bronchi $(\mathrm{p}<0.0001)$, comparable between proximal and distal preparations $(\mathrm{p}=0.24)$.

apparent discrepancies might be that anaesthesiainduced relaxations depend on the muscarinic agonist used [11]. However, other studies have reported a potent relaxant effect of halothane and desflurane on airway smooth muscle even when precontracted with acetylcholine [13, 18]. SAYIner et al. [10] also suggested that volatile anaesthetics could be less effective at preventing contractile responses than at relaxing precontracted preparations (since intracellular mechanisms causing force initiation and force maintenance are different). The results of WIKLUND et al. [18], but not those of FuKushima et al. [14], support this hypothesis. It would be also in accordance with the ability of volatile anaesthetics to attenuate calcium sensitisation [15]. Further studies using human bronchi will be useful to clarify the issue. Meanwhile, the concentration-dependant effect of halothane, isoflurane and desflurane within clinical useful concentrations reported on precontracted animal airway smooth muscle is confirmed on human airway smooth muscle by the present study. As a clinical implication, this strongly supports the view that volatile anaesthetics can provide supplemental (direct) bronchodilation even when the reflex pathway involved in a bronchospasm is no longer active (after removal of the stimulus or pharmacological therapy, for example).

Each of the three volatile anaesthetics tested produced a greater relative relaxation on mildly precontracted airway smooth muscle, when compared to highly precontracted airway smooth muscle (figs. 2a and $b$ versus figs. $2 \mathrm{c}$ and $\mathrm{d}$ ). This confirms and extends the findings reported by ҮАмамото et al. [11] on canine tracheal airway smooth muscle exposed to halothane or isoflurane.

It was found that desflurane relaxed proximal bronchi to a similar extent as halothane and isoflurane (figs. 2a and c). However, this relaxation was mild and was not greater on distal bronchi. This contrasts with the more pronounced effect of halothane (and to a lesser extent, isoflurane) on distal airway smooth muscle (figs. $2 \mathrm{~b}$ and $\mathrm{d}$ versus figs. $2 \mathrm{a}$ and $\mathrm{c}$ ). The airway tree heterogeneity regarding the relaxant effects of volatile anaesthetics has been reported previously $[13,17,20]$. This finding is therefore not surprising in itself. However, for desflurane specifically, it is the opposite of what could be expected from animal studies. Indeed, desflurane appeared to be at least as effective as the other volatile anaesthetics tested on proximal (guinea-pig) airway smooth muscle [18], but was even more effective than the other anaesthetics on distal (canine and rat) airway smooth muscle [13, 17]. In general, the distal airway smooth muscle was found to be more sensitive than the proximal airway smooth muscle with any volatile anaesthetic tested, i.e. with halothane [13], isoflurane [19], sevoflurane [19] and desflurane [13]. In accordance with these results on airway smooth muscle, desflurane was shown to be as effective as halothane, isoflurane or sevoflurane in protecting against methacholine-induced airway constriction in rats in vivo [5]. Desflurane was also reported to cause no airway irritation during various animal trials [22]. Conversely, in humans in vivo, desflurane behaves very differently. Besides its wellrecognised pungency, breath-holding, partial laryngospasm and coughing were often reported during induction of anaesthesia [21]. Desflurane also did not produce bronchodilation during anaesthesia in humans, in contrast to sevoflurane [23]. Nonetheless, these anaesthetic investigations in vivo in humans have been limited to baseline respiratory conditions only, for legitimate safety and ethical reasons. It is therefore difficult to compare these unfavourable effects of desflurane with the potent relaxant effects obtained in animals after a provocative challenge. In that respect, the results of this study, obtained in precontracted human bronchi in vitro, lend more support to a true difference in desflurane-bronchodilating properties in humans. However, that desflurane was poorly effective in human isolated bronchi (versus what could be expected from previous in vitro animal studies) accounts solely in part for the lack of bronchodilation reported in humans in vivo. Thus, other mechanisms, such as irritating reflexes (by-passed in vitro), are likely to be involved in humans in vivo. The fact that lack of bronchodilation or even mild bronchoconstriction was observed mainly in smokers during desflurane anaesthesia (whereas smoking history did not modify sevoflurane bronchodilation) further supports this possibility [23].

Pretreatment with glibenclamide, a $\mathrm{K}_{\mathrm{ATP}}$ channel blocker, approximately halved the relaxant effects produced by $1.33 \mathrm{MAC}$ halothane, isoflurane and desflurane on distal bronchi. This is consistent with several studies that suggest that activation of $\mathrm{K}_{\mathrm{ATP}}$ channels could play a prominent role in volatile anaesthesia-induced relaxation of peripheral airways 
[24], coronary vessels [25], and cerebral vessels [28]. In contrast, FuKushima et al. [14] found that glibenclamide pretreatment did not modify the concentrationdependent relaxation produced by halothane on canine tracheal strips incubated with indomethacin and precontracted with acetylcholine. Differences between contracting stimuli, tracheal versus distal airway smooth muscle, and/or between species may account for these conflicting results. Another explanation may be due to the preparation method. PARK and coworkers $[16,17]$ have clearly shown that indomethacin incubation considerably attenuated rat distal bronchorelaxation produced by halothane, isoflurane, desflurane and sevoflurane in vitro. In addition, PATEL et al. [29] recently identified two-pore-domain background $\mathrm{K}^{+}$channels activated either by volatile anaesthetics or arachidonic acid. Whatever the explanation, the lower efficacy of desflurane (versus halothane) that was observed in human bronchi cannot be ascribed directly to $\mathrm{K}_{\mathrm{ATP}}$ channel-mediated mechanisms because glibenclamide pretreatment similarly attenuated the relaxations induced by all three anaesthetics (fig. 3). However, studies performed by PARK and coworkers [16, 17] have suggested that epithelial prostanoid and/or nitric oxide (NO) production account for differential effects observed between the four volatile anaesthetics on rat distal bronchi. For desflurane, as for halothane, a prostanoid seemed to play a greater role than NO, whereas the opposite was true for isoflurane and both mechanisms seemed equally important for sevoflurane. The relative contribution of these two mechanisms might well be different in humans. NiETGEN et al. [30] showed on Xenopus frog oocytes that different volatile anaesthetics also affected $\mathrm{m} 1$ and $\mathrm{m} 3$ muscarinic signalling in highly divergent ways. More specifically, halothane, isoflurane and sevoflurane inhibited $\mathrm{m} 3$ muscarinic signalling at all concentrations tested, whereas desflurane induced a biphasic concentration-dependent effect, including an enhancement of $\mathrm{m} 3$ muscarinic signalling at low concentration. Very recently, T-type $\mathrm{Ca}^{2+}$ channels have also been implicated in the relaxation of porcine distal (but not proximal) airway smooth muscle induced by isoflurane and sevoflurane [19]. Inhibition of G-proteins dissociation by halothane with subsequent increase in protein phosphatase activity has also been demonstrated [31] and this accounts for attenuation of $\mathrm{Ca}^{2+}$ sensitisation previously reported [15]. Finally, it has been demonstrated that halothane (at least) induces depletion of sarcoplasmic reticulum $\mathrm{Ca}^{2+}$ content via increased $\mathrm{Ca}^{2+}$ leak through both inositol trisphosphate (IP 3) receptor and ryanodine receptor channels [32]. All these mechanisms recently assessed in vitro in animals could be new ways of gaining a better understanding of the results from this study in isolated human distal bronchi, particularly with regard to desflurane.

In conclusion, halothane, isoflurane and desflurane exerted a similar concentration-dependent relaxation on proximal isolated human bronchi. In contrast, a differential effect was observed on distal bronchi. It is worth noting that desflurane was significantly less effective than halothane on distal human bronchi, contrary to previous reports in animal airway smooth muscle. This confirms the interest of using human tissues for in vitro experiments. It could also partly explain the unfavourable respiratory effects of desflurane reported in anaesthetised humans, despite its potent relaxant effects demonstrated in anaesthetised animals. Similarly, adenosine-triphosphate sensitive $\mathrm{K}^{+}$channel blockade with glibenclamide attenuated the relaxations induced by all three anaesthetics and thus is unlikely to explain the peculiar effect of desflurane on human airways.

\section{References}

1. Hirshman CA, Bergman NA. Halothane and enflurane protect against bronchospasm in an asthma dog model. Anesth Analg 1978; 57: 629-633.

2. Shah MV, Hirshman CA. Mode of action of halothane on histamine-induced airway constriction in dogs with reactive airways. Anesthesiology 1986; 65: $170-174$.

3. Vettermann J, Beck KC, Lindahl SGE, Brichant J-F, Rehder K. Actions of enflurane, isoflurane, vecuronium, atracurium, and pancuronium on pulmonary resistance in dogs. Anesthesiology 1988; 69: 688-695.

4. Warner DO, Vettermann J, Brichant J-F, Rehder K. Direct and indirect effects of halothane on pulmonary resistance in vivo. Anesthesiology 1990; 72: 1057-1063.

5. Habre W, Petak F, Sly PD, Hantos Z, Morel DR. Protective effects of volatile agents against methacholineinduced bronchoconstriction in rats. Anesthesiology 2001; 94: 348-353.

6. Heneghan CPH, Bergman NA, Jordan C, Lehane JR, Catley DM. Effect of isoflurane on bronchomotor tone in man. Br J Anaesth 1986; 58: 24-28.

7. Rooke GA, Choi J-H, Bishop MJ. The effect of isoflurane, halothane, sevoflurane, and thiopental/ nitrous oxide on respiratory system resistance after tracheal intubation. Anesthesiology 1997; 86: 1294 1299.

8. Korenaga S, Takeda K, Ito Y. Differential effects of halothane on airway nerves and muscle. Anesthesio$\log y$ 1984; 60: 309-318.

9. Brichant J-F, Gunst SJ, Warner DO, Rehder K. Halothane, enflurane, and isoflurane depress the peripheral vagal motor pathway in isolated canine tracheal smooth muscle. Anesthesiology 1991; 74: 325-332.

10. Sayiner A, Lorenz RR, Warner DO, Rehder K. Bronchodilation by halothane is not modulated by airway epithelium. Anesthesiology 1991; 75: 75-81.

11. Yamamoto K, Morimoto N, Warner DO, Rehder K, Jones KA. Factors influencing the direct actions of volatile anesthetics on airway smooth muscle. Anesthesiology 1993; 78: 1102-1111.

12. Mercier FJ, Denjean A. Guinea-pig tracheal responsiveness in vitro following general anaesthesia with halothane. Eur Respir J 1996; 9: 1451-1455.

13. Mazzeo AJ, Cheng EY, Bosnjak ZJ, Coon RL, Kampine JP. Differential effects of desflurane and halothane on peripheral airway smooth muscle. $\mathrm{Br}$ J Anaesth 1996; 76: 841-846.

14. Fukushima T, Hirasaki A, Jones KA, Warner DO. Halothane and potassium channels in airway smooth muscle. Br J Anaesth 1996; 76: 847-853.

15. Kai T, Bremerich DH, Jones KA, Warner DO. Drug-specific effects of volatile anesthetics on $\mathrm{Ca}^{2+}$ 
sensitization in airway smooth muscle. Anesth Analg 1998; 87: 425-429.

16. Park KW, Dai HB, Lowenstein E, Kocher ON, Sellke FW. Isoflurane- and halothane-mediated dilation of distal bronchi in the rat depends on the epithelium. Anesthesiology 1997; 86: 1078-1087.

17. Park KW, Dai HB, Lowenstein E, Sellke FW. Epithelial dependence of the bronchodilatory effect of sevoflurane and desflurane in rat distal bronchi. Anesth Analg 1998; 86: 646-651.

18. Wiklund CU, Lim S, Lindsten U, Lindahl SGE. Relaxation by sevoflurane, desflurane and halothane in the isolated guinea-pig trachea via inhibition of cholinergic neurotransmission. Br J Anaesth 1999; 83: 422-429.

19. Yamakage M, Chen X, Tsujiguchi N, Kamada Y, Namiki A. Different inhibitory effects of volatile anesthetics on T- and L-type voltage-dependent $\mathrm{Ca}^{2+}$ channels in porcine tracheal and bronchial smooth muscles. Anesthesiology 2001; 94: 683-693.

20. Brown RH, Zerhouni EA, Hirshman CA. Comparison of low concentrations of halothane and isoflurane as bronchodilators. Anesthesiology 1993; 78: 10971101.

21. Warltier DC, Pagel PS. Cardiovascular and respiratory actions of desflurane: is desflurane different from isoflurane? Anesth Analg 1992; 75: S17-S31.

22. Clarke KW. Desflurane and sevoflurane. New volatile anesthetic agents. Vet Clin North Am Small Anim Pract 1999; 29: 793-810.

23. Goff MJ, Arain SR, Ficke DJ, Uhrich TD, Ebert TJ. Absence of bronchodilation during desflurane anesthesia: a comparison to sevoflurane and thiopental. Anesthesiology 2000; 93: 404-408.
24. Mehr EH, Lindeman KS. Effects of halothane, propofol, and thiopental on peripheral airway reactivity. Anesthesiology 1993; 79: 290-298.

25. Yost CS. Potassium channels. Basic aspects, functional roles, and medical significance. Anesthesiology 1999; 90: 1186-1203.

26. Quasha AL, Eger EI II, Tinker JH. Determination and applications of MAC. Anesthesiology 1980; 53: 315-334.

27. Bazil CW, Raux EM, Yudell S, Minneman KP. Equilibration of halothane with brain tissue in vitro: comparison to brain concentrations during anesthesia. J Neurochem 1987; 49: 952-958.

28. Iida $\mathrm{H}$, Ohata $\mathrm{H}$, Iida $\mathrm{M}$, Watanabe $\mathrm{Y}$, Dohi $\mathrm{S}$. Isoflurane and sevoflurane induce vasodilation of cerebral vessels via ATP-sensitive $\mathrm{K}^{+}$channel activation. Anesthesiology 1998; 89: 954-960.

29. Patel AJ, Honoré E, Lesage F, Fink M, Romey G, Lazdunski M. Inhalational anesthetics activate twopore-domain background $\mathrm{K}^{+}$channels. Nat Neurosci 1999; 2: 422-426.

30. Nietgen GW, Honemann CW, Chan CK, Kamatchi GL, Durieux ME. Volatile anaesthetics have differential effects on recombinant $\mathrm{m} 1$ and $\mathrm{m} 3$ muscarinic acetylcholine receptor function. Br J Anaesth 1998; 81: 569-577.

31. Hanazaki M, Jones JA, Perkins WJ, Warner DO. Halothane increases smooth muscle protein phosphatase in airway smooth muscle. Anesthesiology 2001; 94 : 129-136.

32. Pabelick CM, Prakash YS, Kannan MS, Warner DO, Sieck GC. Effects of halothane on sarcoplasmic reticulum calcium release channels in porcine airway smooth muscle. Anesthesiology 2001; 95: 207-215. 